\title{
Protective effect of kumquat fruits and carrot seeds extracts against brain aging in rats
}

\author{
Doha Abdou Mohamed $^{1}{ }^{\mathbb{D}}$, Karem Fouda $^{(\mathbb{D}}$, Ibrahim Mohamed Hamed $^{1^{*}}{ }^{\mathbb{D}}$, Sherein S. Abdelgayed ${ }^{(\mathbb{D}}$ \\ ${ }^{1}$ Nutrition and Food Sciences Department, National Research Centre, Dokki, Cairo, Egypt \\ ${ }^{2}$ Pathology Department, Faculty of Veterinary Medicine, Cairo University, Cairo, Egypt
}

\section{A R T I C L E I N F 0}

Article Type:

Original Article

\section{Article History:}

Received: 16 March 2019

Accepted: 7 July 2019

\section{Keywords:}

Brain aging

D-galactose

Kumquat

Carrot seeds

Antioxidant.

\begin{abstract}
A B S T R A C T
Introduction: Protection of brain against accelerated aging helps avoiding the occurrence of neurodegenerative diseases. So, the current work was conducted to evaluate the rescuing role of kumquat fruits crude ethanol extract, carrot seeds ethanol and petroleum ether extracts against the brain aging induced by $\mathrm{D}$-galactose in rats.

Methods: Forty male Sprague Dawley rats were divided equally into five groups. Group I was served as normal control, rats of group II were daily injected intraperitoneally (i.p.) with $150 \mathrm{mg} / \mathrm{kg}$ BW of D-galactose. Rats of group III, IV and V were daily injected i.p. with the same dose of D-galactose and administered orally with $250 \mathrm{mg} / \mathrm{kg} \mathrm{BW} /$ day of kumquat fruits crude ethanol extract, carrot seeds ethanol extract and carrot seeds petroleum ether extract, respectively. After 6 weeks the rats were scarified, brain tissues were analyzed for malondialdehyde (MDA), catalase (CAT) as well as histological examination. Also, the plasma was analyzed for MDA, tumor necrosis factor- $\alpha$ (TNF- $\alpha$ ), creatinine and urea levels, as well as CAT, butyrylcholinesterase (BChE), aspartate transaminase (AST) and alanine transaminase (ALT) activities.

Results: From the results, it was elucidated that the tested extracts suppressed both the reduction in CAT and the elevation in MDA either in brain or plasma and the increase in plasma TNF- $\alpha$, BChE as well as liver and kidney parameters.

Conclusion: The tested extracts can be served as potent protective agents against the accelerated aging parameters which may be due to anti-oxidant and anti-inflammatory activities.
\end{abstract}

Implication for health policy/practice/research/medical education:

Kumquat fruits and carrot seeds crude ethanol extracts can be served as potent protective agents against accelerated aging.

Please cite this paper as: Mohamed DA, Fouda K, Hamed IM, Abdelgayed SS. Protective effect of kumquat fruits and carrot seeds extracts against brain aging in rats. J Herbmed Pharmacol. 2019;8(4):287-294. doi: 10.15171/jhp.2019.42.

\section{Introduction}

Aging is a complex natural phenomenon not only associated with the age but also with the environmental factors which contribute to free radicals production (1). Brain aging may be one of the causes of several neurodegenerative diseases, such as Parkinson's disease, mild cognitive impairment as well as Alzheimer's disease (2). Brain aging is related to mitochondrial dysfunction which is combined with increased free radical production especially that the brain is more prone to oxidative stress and senescence due to the high content of lipid and high oxygen consumption (3). In this context, the use of natural antioxidants may be effective in the protection of brain against the accelerated aging. $\mathrm{D}$-galactose (D-gal) can mimic aging in animal models by inducing oxidative stress and inflammation (4). D-gal accumulation elevates oxidative stress due to elevation of reactive oxygen species (ROS). Elevation of ROS induces glycation of amino peptides and proteins. Also, this accumulation leads to downstream activation of nuclear factor kappa B (NF$\kappa \mathrm{B})$, followed by release of ROS and pro-inflammatory mediators (4).

Kumquat (In Chinese means golden orange) is one of the smallest citrus fruits (Figure 1), which is characterized by the acidic taste of flesh and soft edible peel, where the fruit can be eaten along with the peel either in the form 
of row fruit or as juice. It can also be used as pickles and marmalades (5). Beside the nutrients, in kumquat there are several phytochemicals in fruits including carotenoids, essential oils, ascorbic acid as well as flavonoids (6). Such phytochemicals, with various beneficial biological effects, provide kumquat a great importance as a folk medicine (7). Allam et al (8) demonstrated the hypocholesterolemic effect of kumquat. According to Dosoky and Setzer (9) kumquat exhibited antifungal, antibacterial as well as antioxidant activities. Also Nouri and Shafaghatlonbar (10) declared that the essential oil of kumquat was considered a potent antioxidant. Carrot seeds (Figure 1) produced when flowering process is induced; and the plant turns from the vegetative phase to the reproductive phase thus producing a rod or floral tassel at the end of it an umbels which carry the seeds (11). Although the carrot plant is planted primarily with the aim of obtaining roots, but the seeds are used as a flavoring agent in many food products and cosmetics in addition to its utilization as medicinal purposes. Carrot seeds oil not only has antioxidant effect but also possesses counteractive role for several disease such as cancer, diabetes and inflammation (12). Ethanol extract of carrot seeds possessed hepatoprotective impact against thioacetamide (13). Also, Shebaby et al (14) proved that oil fractions of carrot had hepatoprotective effect against carbon tetra chloride. Carotol, one of the compounds found in the carrot seeds oil attributed to its antifungal effect (15) and pleasurable aroma and taste (12). Kumarasamy et al (16) suggested that luteolin was responsible for the antibacterial activity of methanol extract of carrot seeds. The current study was designed to estimate the rescuing role of kumquat fruits crude ethanol extract, carrot seeds ethanol and petroleum ether extracts against the brain aging induced by $\mathrm{D}$-galactose in rats.

\section{Materials and Methods}

Materials

\section{Plant samples}

Carrot seeds (Figure 1) (Daucus carota L., Family Apiaceae) and kumquats fruit (Figure 1) (Citrus japonica, Family Rutaceae) were purchased from local markets, Cairo, Egypt.

\section{Animals}

Forty male Sprague Dawley rats, 133-178 g were used. Animals were kept individually in stainless steel cages at room temperature of $25 \pm 2^{\circ} \mathrm{C}$ and a relative humidity of about 55\%; water and food were given ad libitum.

Diets

A balanced diet composed of $10 \%$ protein supplemented from casein, $10 \%$ corn oil, $23.5 \%$ sucrose, $47 \%$ maize starch, 5\% fiber, $3.5 \%$ salt mixture (17) and $1 \%$ vitamin mixture (18) was prepared for feeding animals all over the experimental period.

\section{Materials and Methods}

Preparation of crude ethanol extract of kumquat fruits. Kumquat fruits were washed by tap water and cutting to small slices, then dried using Solar furnaces. The dried kumquat fruits were powdered and extracted successively in a continuous extraction apparatus (soxhlet) until exhaustion with ethanol for preparation of crude ethanol extract. The solvent was completely removed by evaporation under reduced pressure at a temperature not exceeding $40^{\circ} \mathrm{C}$. Crude extract of kumquats fruits was kept in deep-freeze till used.

\section{Preparation of carrot seeds oil}

The oil was extracted from crushed seeds with petroleum ether $\left(40-60^{\circ} \mathrm{C}\right)$ in a Soxhlet apparatus. The extract was evaporated in vacuum. The lipid extract was collected in a flask. The extracted lipid was weighed to determine the oil content and stored under nitrogen at $4^{\circ} \mathrm{C}$ for further analysis.

\section{Preparation of ethanol extract of the carrot seeds}

The defatted meal of carrot seeds was extracted with ethanol in a Soxhlet apparatus. The solvent was completely removed by evaporation under reduced pressure at a temperature not exceeding $40^{\circ} \mathrm{C}$. The ethanol extract was stored in deep-freeze till used.

\section{Total phenolic content}

The Folin-Ciocalteu assay, adapted from Singleton and Rossi (19), was used for the determination of total phenolics present in the crude ethanol extract of kumquat fruits and ethanol extract of carrot seeds. Total phenolics were calculated with respect to gallic acid standard curve (concentration range: $0-12 \mu \mathrm{g} \mathrm{mL}^{-1}$ ). Results are expressed in $\mathrm{mg}$ of gallic acid $\mathrm{g}^{-1}$ of extract.
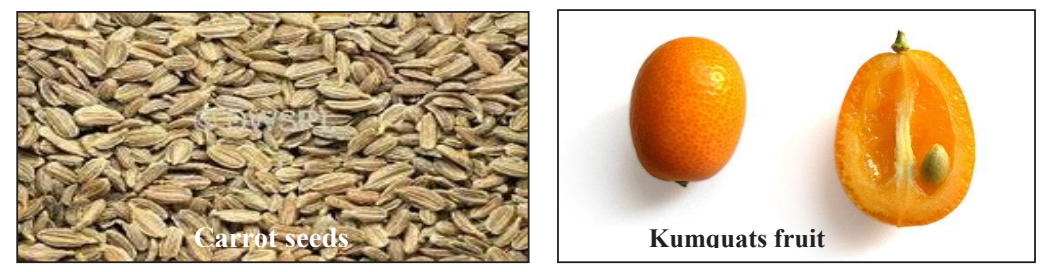

Figure 1. Kumquats fruit and carrot seeds. 


\section{Total flavonoid content}

Total flavonoids in the crude ethanol extract of kumquat fruits and ethanol extract of carrot seeds were measured using a colorimetric assay adapted from Zhishen et al (20). Total flavonoids were calculated with respect to quercetin standard curve (concentration range: 50-200 $\mu \mathrm{g} \mathrm{mL}^{-1}$ ). Results are expressed in $\mathrm{mg}$ of quercetin $\mathrm{g}^{-1}$ extract.

\section{Assessment of fatty acids of carrot seeds oil}

Fatty acid methyl esters of carrot seeds oil were prepared according to AOAC (21) to be subjected to GLC analysis of fatty acids. Assessment of the methyl ester was carried out by injecting $2 \mu \mathrm{L}$ into a Hewlett Packard HP-system 6890 gas chromatograph equipped with FID. HP-5 capillary column $(30 \mathrm{~m} \times 0.32 \mathrm{~mm}$ i.d.; 0.25 um film thickness) was used to separate the different methyl esters. The chromatographic analysis conditions were: initial temperature $70^{\circ} \mathrm{C}$ with a hold for 1 minute, then rose to $120^{\circ} \mathrm{C}$ at a rate of $40^{\circ} \mathrm{C} / \mathrm{min}$ with 2 minutes hold then the temperature was finally raised to $220^{\circ} \mathrm{C}$ at a rate of $4^{\circ} \mathrm{C}$ $/$ min with another 20 minutes hold. The injector and detector temperatures were $250^{\circ} \mathrm{C}$ and $280^{\circ} \mathrm{C}$ respectively. Identification of the fatty acid methyl esters were carried out by direct comparison of retention times of each of the separated compounds with standards of the fatty acid methyl esters analyzed under the same conditions. Quantization was based on peak area integration.

\section{Design of the animal experiment}

After one week of adaptation the animals were divided into five groups ( $\mathrm{n}=8$, each). Group I was served as control group (normal group). Rats of group II were daily injected i.p. with $150 \mathrm{mg} / \mathrm{kg} \mathrm{BW}$ of D-galactose (D-gal group). Rats of group III were daily injected i.p. with the same dose of D-gal and administered orally with $250 \mathrm{mg} / \mathrm{kg} / \mathrm{d}$ of kumquat crude ethanol extract (kumquat ethanol extract group). Rats of group IV were daily injected i.p. with the same dose of D-gal and administered orally with $250 \mathrm{mg} /$ $\mathrm{kg} / \mathrm{d}$ of carrot seeds ethanol extract (carrot seeds ethanol extract group) while the animals of group V were daily injected i.p. with the same dose of D-gal and administered orally with $250 \mathrm{mg} / \mathrm{kg} / \mathrm{d}$ of carrot seeds petroleum ether extract (carrot seeds petroleum ether extract group). The experiment lasted 6 weeks during which all rats were fed on balanced diet also body weight and food intake were recorded weekly. At the end of the study total food intake, body weight gain and feed efficiency ratio were calculated. At the end of the study, rats were anesthetized using ether and the blood was withdrawn from all rats after an overnight fast. Rats were dissected and brain was immediately separated from each rat and weighed then part of each brain was immersed in $10 \%$ formaldehyde solution for histological examination while the other part was immediately analyzed for malondialdehyde (MDA) as indicator of lipid peroxidation according to Satoh (22) and catalase (CAT) according to Aebi (23). Also, plasma MDA and CAT were determined according to the same mentioned methods. Tumor necrosis factor- $\alpha$ (TNF- $\alpha$ ) was assayed as inflammatory biomarker using Eliza technique. Plasma butyrylcholinesterase (BChE) activity was estimated according to the method of Vaisi-Raygani et al (24). In addition, plasma was analyzed for the activities of aspartate transaminase (AST) and alanine transaminase (ALT) according to Reitman and Frankel (25) as well as creatinine and urea according to the methods of Houot (26) and Fawcett and Scott (27), respectively.

Statistical analysis

Statistical analyses were done using SPSS version 22 . The results were expressed as mean \pm standard error (SE) and analyzed statistically using one-way analysis of variance (ANOVA) followed by Duncan test. The statistical significance of difference was taken as $P \leq 0.05$.

\section{Results}

As shown in Table 1, carrot seeds ethanol extract recorded the highest contents of both total phenolic and total flavonoids (36.4 mg GAE/g extract and $10.6 \mathrm{mg} / \mathrm{g}$ extract, respectively).

Table 2 shows the fatty acid profile of carrot seeds oil. Palmitic acid (4.76\%) was the major saturated fatty acid presence in the carrot seeds oil. Oleic acid (76.75\%) was the major unsaturated fatty acid presence in carrot oil.

Table 1. Total phenolic (mg GAE/g extract) and total flavonoid (mg/g extract) contents of kumquat and carrot seeds ethanol extracts

\begin{tabular}{lcc}
\hline \multicolumn{1}{c}{ Extract } & $\begin{array}{c}\text { Total phenolic content } \\
\text { (mg GAE/g extract) }\end{array}$ & $\begin{array}{c}\text { Total flavonoids } \\
\text { (mg/g extract) }\end{array}$ \\
\hline $\begin{array}{l}\text { Kumquat crude } \\
\text { ethanol extract }\end{array}$ & $30 \pm 1.283$ & $8.1 \pm 0.439$ \\
$\begin{array}{l}\text { Carrot seeds ethanol } \\
\text { extract }\end{array}$ & $36.4 \pm 1.436$ & $10.6 \pm 0.572$ \\
\hline
\end{tabular}

Table 2. Fatty acids contents of carrot seeds petroleum ether extract (oil) (as percentage of total fatty acids)

\begin{tabular}{lc}
\hline Fatty acids (\%) & Carrot seeds oil \\
\hline Caprylic acid (C8:0) & 1.02 \\
Capric acid (C10:0) & 0.263 \\
Lauric acid (C12:0) & 1.66 \\
Myristic acid (C14:0) & 0.244 \\
Palmitic acid (C16:0) & 4.76 \\
Oleic acid (C18:1) $\omega-9$ & 76.75 \\
Linoleic acid (C18:2) $\omega-6$ & 7.13 \\
Linolenic acid (C18:2) $\omega-3$ & 0.185 \\
Total saturated fatty acids & 7.947 \\
Total unsaturated fatty acids & 84.063 \\
\hline
\end{tabular}


Total saturated fatty acids were present by $7.947 \%$ in carrot oil, while total unsaturated fatty acids were present by $84.063 \%$. The present results revealed that carrot oil is rich in mono-unsaturated fatty acids (MUSFs), especially oleic acid $(\omega-9)$.

The biochemical parameters of brain tissue and plasma of the studied groups are summarized in Table 3. It was evident that the injection with $\mathrm{D}$-gal mediated oxidative stress which observed via the elevation of MDA and the reduction of CAT either in brain tissue or in the plasma. On the other side, the oral administration of kumquat fruits crude ethanol extract, carrot seeds ethanol extract or carrot seeds petroleum ether extract suppressed the elevation of MDA and the reduction of CAT either in brain tissue or in the plasma and thus attenuated the oxidative stress. Carrot seeds ethanol extract was the most promising in this concern. Rats which injected with D-gal and had no treatment exhibited the highest levels of BChE and TNF- $\alpha$. The rats which were orally administrated with the studied extracts suppressed the raising of BChE and TNF-a. Also carrot seeds ethanol extract was the most promising in this concern. The liver functions (indicated by AST and ALT levels) as well as the kidney functions (indicated by urea and creatinine levels) significantly increased in the rats of D-gal group. On the other hand, the studied extracts combated the elevations of both liver and kidney functions.

From the data tabulated in Table 4, it was evident that a significant reduction in the final body weight was caused by the injection of D-gal. On this basis, rats which were injected D-gal only, recorded the lowest body weight gain. This group also recorded the lowest total food intake, while the administration of kumquat crude ethanol extract, carrot seeds ethanol extract or carrot seeds petroleum ether extract improved the body weight gain.

Histopathological examination of brain tissue.

The histopathological examination of brain tissue of the rats of normal control group showed normal brain tissue, normal nerve cells and nerve fibers (H\&E X400) (score lesions: 0) (Figure 2A). Brain tissue of D-gal control group showed vacuolated nerve cells (arrows) and demyelinated nerve fibers (H\&E X400) (score lesions: +++ ) (Figure 2B). Brain tissue of D-gal control group showed diffuse gliosis; proliferated and aggregated glia cells (arrow in Figure 2C; score lesions: +++$)(\mathrm{H} \& \mathrm{E} \mathrm{X} 400)$. As it can

Table 3. Biochemical parameters of different experimental groups

\begin{tabular}{|c|c|c|c|c|c|}
\hline & Normal control & $\begin{array}{c}\text { D-Galactose } \\
\text { control }\end{array}$ & $\begin{array}{l}\text { kumquat crude } \\
\text { ethanol extract }\end{array}$ & $\begin{array}{c}\text { Carrot seeds ethanol } \\
\text { extract }\end{array}$ & $\begin{array}{c}\text { Carrot seeds petroleum } \\
\text { ether extract }\end{array}$ \\
\hline \multicolumn{6}{|l|}{ Brain tissue } \\
\hline CAT (U/g tissue) & $657.25^{d} \pm 8.53$ & $409.50^{a} \pm 7.37$ & $624.84^{c} \pm 4.10$ & $657.50^{d} \pm 6.05$ & $554.17^{b} \pm 7.94$ \\
\hline MDA (nmol/g tissue) & $11.27^{\mathrm{a}} \pm 0.36$ & $23.30^{d} \pm 0.32$ & $14.01^{b} \pm 0.41$ & $13.30^{\mathrm{b}} \pm 0.44$ & $15.36^{c} \pm 0.43$ \\
\hline \multicolumn{6}{|l|}{ Plasma } \\
\hline CAT (U/L) & $462.99^{d} \pm 3.96$ & $328.14^{\mathrm{a}} \pm 9.34$ & $387.78^{b} \pm 6.86$ & $450.09^{c d} \pm 6.07$ & $436.83^{c} \pm 8.35$ \\
\hline $\mathrm{MDA}(\mathrm{nmo} / \mathrm{mL})$ & $5.10^{\mathrm{a}} \pm 0.36$ & $9.57^{b} \pm 0.30$ & $5.65^{\mathrm{a}} \pm 0.42$ & $5.26^{a} \pm 0.52$ & $6.22^{\mathrm{a}} \pm 0.39$ \\
\hline TNF- $\alpha(\mathrm{pg} / \mathrm{mL})$ & $14.29^{\mathrm{a}} \pm 0.30$ & $29.87^{d} \pm 0.83$ & $25.50^{c} \pm 0.69$ & $19.37^{b} \pm 0.57$ & $24.62^{c} \pm 0.57$ \\
\hline $\mathrm{BChE}(\mathrm{U} / \mathrm{L})$ & $315.52^{\mathrm{a}} \pm 5.58$ & $511.56^{d} \pm 10.02$ & $370.91^{c} \pm 7.67$ & $325.23^{\mathrm{ab}} \pm 9.71$ & $342.11^{b} \pm 7.48$ \\
\hline AST (IU/L) & $19.50^{\mathrm{a}} \pm 1.08$ & $28.50^{c} \pm 1.65$ & $25.75^{b c} \pm 0.98$ & $23.50^{b} \pm 1.13$ & $23.87^{b} \pm 1.57$ \\
\hline ALT (IU/L) & $10.37^{a} \pm 0.70$ & $23.00^{c} \pm 1.35$ & $14.62^{b} \pm 1.16$ & $10.62^{\mathrm{a}} \pm 0.90$ & $16.37^{b} \pm 1.24$ \\
\hline Creatinine (mg/dL) & $0.77^{a} \pm 0.02$ & $1.21^{\mathrm{d}} \pm 0.03$ & $1.06^{c} \pm 0.04$ & $0.93^{b} \pm 0.04$ & $0.94^{b} \pm 0.03$ \\
\hline Urea (mg/dL) & $30.35^{\mathrm{a}} \pm 1.06$ & $40.65^{c} \pm 1.63$ & $35.22^{b} \pm 1.65$ & $29.35^{a} \pm 0.88$ & $28.02^{\mathrm{a}} \pm 1.03$ \\
\hline
\end{tabular}

Data are expressed as mean $\pm \mathrm{SE}$.

Values with different superscript letters in the same row are significantly different at $P<0.05$ levels.

Table 4. Nutritional parameters of different experimental groups

\begin{tabular}{|c|c|c|c|c|c|c|}
\hline Groups & $\begin{array}{l}\text { Initial body } \\
\text { weight (g) }\end{array}$ & $\begin{array}{l}\text { Final body } \\
\text { weight (g) }\end{array}$ & $\begin{array}{l}\text { Body weight } \\
\text { gain (g) }\end{array}$ & $\begin{array}{l}\text { Total food } \\
\text { intake (g) }\end{array}$ & $\begin{array}{l}\text { Feed efficiency } \\
\text { ratio }\end{array}$ & $\begin{array}{l}\text { Relative brain } \\
\text { weight }\end{array}$ \\
\hline Normal & $155.50^{\mathrm{a}} \pm 3.70$ & $262.62^{\mathrm{c}} \pm 2.92$ & $107.12^{\mathrm{d}} \pm 3.78$ & $539.25^{c} \pm 6.26$ & $0.20^{b} \pm 0.01$ & $0.61^{\mathrm{a}} \pm 0.01$ \\
\hline D-Galactose & $155.12^{\mathrm{a}} \pm 5.70$ & $235.62^{\mathrm{a}} \pm 6.45$ & $80.50^{\mathrm{a}} \pm 2.48$ & $456.50^{a} \pm 6.20$ & $0.18^{a} \pm 0.01$ & $0.63^{\mathrm{ab}} \pm 0.02$ \\
\hline Kumquat crude ethanol extract & $155.25^{\mathrm{a}} \pm 2.87$ & $253.50^{\mathrm{bc}} \pm 2.99$ & $98.25^{c} \pm 2.78$ & $536.12^{\mathrm{c}} \pm 4.45$ & $0.18^{\mathrm{ab}} \pm 0.01$ & $0.61^{\mathrm{a}} \pm 0.02$ \\
\hline Carrot seeds ethanol extract & $155.12^{\mathrm{a}} \pm 3.16$ & $260.50^{c} \pm 3.34$ & $105.37^{c d} \pm 2.61$ & $537.37^{c} \pm 3.25$ & $0.20^{\mathrm{b}} \pm 0.01$ & $0.61^{\mathrm{a}} \pm 0.01$ \\
\hline Carrot seeds petroleum ether extract & $155.00^{\mathrm{a}} \pm 2.14$ & $245.25^{\mathrm{ab}} \pm 2.08$ & $90.25^{\mathrm{b}} \pm 1.92$ & $485.25^{b} \pm 7.07$ & $0.19^{\mathrm{ab}} \pm 0.01$ & $0.67^{b} \pm 0.01$ \\
\hline
\end{tabular}

Data are expressed as mean $\pm \mathrm{SE}$.

Values with different superscript letters in the same row are significantly different at $P<0.05$ levels. 
be seen in Figure 2D \& 2E, the brain tissue of rats given kumquat crude ethanol extract showed improved brain tissue with congested blood vessels (arrow), (H\&E X400) (score lesions: ++ ). Brain tissue of rats given carrot seeds ethanol extract (Figure 2F \& 2G) showed normal nerve cells and nerve fibers (H\&E X400) (score lesions: 0). Brain tissue of the rats given carrot seeds oil (Figure $2 \mathrm{H}$ ) showed slightly congested blood vessel (arrow) (H\&E X400) (score lesions: + ). Also, brain tissue of the rats given carrot seeds oil (Figure 2I) showed intraneural edema with vacuolated nerve cells (arrow) (H\&E X400) (score lesions: +).

\section{Discussion}

Aging is age related process however, it can be accelerated by various factors such as stress, environmental factors and nutritional deficiencies (28). Food and plant bioactive compounds can help slow down aging (29-31). In the present study aging was progressed in rats via the injection of D-gal which demonstrated to mediate the brain aging process in mice and rats in several studies (32-34). Fatemi et al (32) declared that oxidative stress was mediated by $\mathrm{D}$-gal through not only the reduction in the antioxidant enzyme activities but also through catalyzing free radicals production. Thus, the brain aging can be developed by oxidative damage and inflammation. Indeed, the results of the present study pointed to the occurrence of oxidative stress via the injection of D-gal which demonstrated by the reduction in CAT as one of the antioxidant enzymes and elevation in MDA either in brain tissue or in plasma. Also, our results indicated the incidence of inflammation following injection of D-gal which could be observed via the elevation in TNF- $\alpha$. It was confirmed via the results that the oral administration of kumquat fruits crude ethanol extract, carrot seeds ethanol extract or carrot seeds petroleum ether extract (at dose $250 \mathrm{mg} / \mathrm{kg} \mathrm{BW}$ ) suppressed the reduction in CAT and elevation in MDA either in brain tissue or in plasma. Also, administration of the mentioned items reversed the raising of TNF- $\alpha$ as well as liver and kidney functions. These effects of the studied extracts may be attributed to their contents of the bioactive components. Lou et al (35) reported that poncirin, phloretin, rhoifolin, acacetin and apigenin-8C-neohesperidoside among the flavonoids in kumquat to which various biological activities such as anti-oxidant and anti- inflammatory can be attributed. Also, the antioxidant and anti-inflammatory activities of kumquat may be contributed to its content of d-limonene (36). The brain anti-aging impact of kumquat may be attributed to its content of polyphenols such as kaempferol, luteolin, hesperidin and quercetin (7). Sarubbo et al (37) stated that polyphenol possess brain anti-aging effect. Also the improvement of the memory, learning, as well as the motor coordination by polyphenols may be originated from their ability to attenuate the oxidative stress and inflammation (via modification of NF- $\kappa B$ levels and cytokines). Additionally, kumquat according to Hosseini et al (38) is a good source of vitamin C to which the protective effect of kumquat fruits against brain aging may be attributed. Monacelli et al (39) declared that oxidative stress, over production of the inflammatory agents, telomere attrition, as well as chromatin disorganization can be suppressed by vitamin C. Also, the two hallmarks of biological aging (immune-senescence and inflammaging) can be modulated by vitamin $\mathrm{C}$.

Mani and Parle (40) concluded that the elevation in acetyl cholinesterase activity and the memory deficits can be reversed by the oral administration of carrot seeds extract. Mani et al (41) suggested the beneficial effect of carrot seeds in Alzheimer's disease. Our results pointed to the superiority of carrot seeds ethanol extracts in the
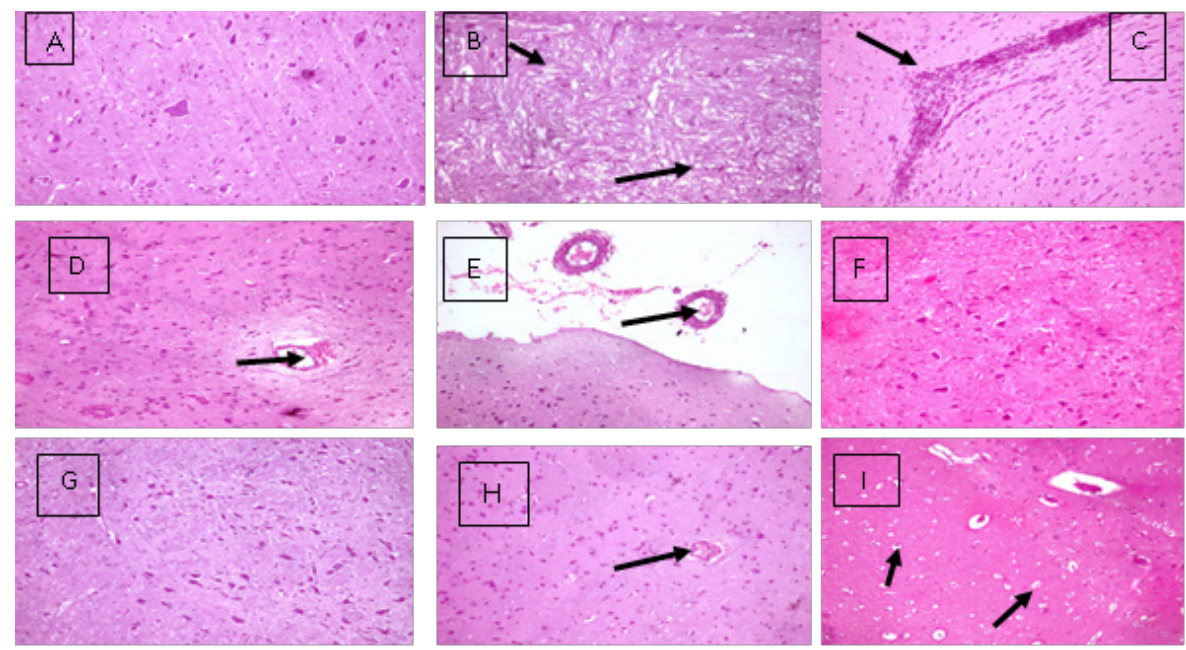

Figure 2. Histopathological examination of brain tissue of the rats in different groups.

(A): Brain tissue of normal control (H\&E X400). (B \& C): Brain tissue of D-galactose control (H\&E X400). (D \& E): Brain tissue of rats given kumquat crude ethanol extract. ( $F \& G$ ): Brain tissue of rats given ethanol extract of carrot seeds. (H \& I): Brain tissue of rats given carrot seeds oil. 
protection against the negative effect of D-gal might be due to the high content of phenolic compounds and flavonoids as found in the present study. Also, Ksouri et al (42) reported that the methanol extract of carrot seeds exhibited high radical-scavenging activity more than a-tocopherol. Rezaei-Maghadam et al (43) confirmed the antioxidant activity of ethanol carrot seeds extract and its ability to suppress the lipid peroxidation in the liver tissue. Flavones in carrot seeds including apigenin, kaempferol, luteolin, luteolin 3-O- $\beta-\mathrm{D}$-glucopyranoside and luteolin $4-\mathrm{O}-\beta-\mathrm{D}$-glucopyranoside contribute in the antioxidant activity of carrot seeds (44). Such flavonoids have the ability of free radicals scavenging and metal chelating in addition to the inhibition of the generative enzymes of free radicals including lipoxygenase, nitric oxide synthase, cyclooxygenase, xanthin oxidase as well as monoamine oxidase (45).

The anti-aging effect of carrot seeds petroleum ether extract (oil) may be attributed to the presence of oleic acid as monounsaturated fatty acid. Fatty acids stimulate gene expression and neuronal activity, boost synaptogenesis and neurogenesis, and prevent neuro-inflammation and apoptosis. By doing so, they promote brain development, ameliorate cognitive functions, serve as anti-depressants and anticonvulsants, bestow protection against traumatic insults, and enhance repairing processes (46). It was reported that intake of sufficient quantity of MUFAs prevented the age related deletion of mitochondrial DNA in the brain of aged animals (47). In this regards, palmitic acid (16:0), stearic acid (18:0), upstreamn-3 PUFAs, and $\mathrm{AA}(20: 4 n-6)$ triggered higher secretion of $A \beta$ peptide compared to long chain downstream n-3 PUFAs and MUFAs (48). It also was reported that oleic acid supplementation in a mouse model of Alzheimer's disease reduced AD-type neuropathology (49).

\section{Conclusion}

Oral administration of kumquat fruits crude ethanol extract, carrot seeds ethanol extract or carrot seeds petroleum ether extract could reverse the negative effects of D-galactose in rats including the reduction in CAT and the elevation in MDA either in brain or in plasma and the elevation in plasma TNF- $\alpha$, BChE as well as the liver and kidney functions. On this basis, it was concluded that the studied extracts have promising protective effect against the accelerated brain aging. Carrot seeds ethanol extract had the most promising effect in this concern. These beneficial effects may be due to the bioactive components with anti-oxidant and anti-inflammatory properties of the tested extracts.

\section{Authors' contributions}

DM designed all experimental works; prepared plants extracts, contributed in the analysis of tissue samples and wrote the final manuscript and the final reviewing of the manuscript. KF participated in all animal interventions (animal experiment and blood analysis), made the statistical analysis of the results, prepared the final tables of the manuscript and contributed in writing the manuscript. IM contributed in designing the biological part and in writing the manuscript. The histological examination was done by SSA. The final paper was read and approved by all authors for publication.

\section{Conflict of interests}

The authors declare no conflicts of interest.

\section{Ethical considerations}

Ethical issues including plagiarism, misconduct, data fabrication, falsification, double publication or submission have been carefully checked by authors. The animal experiments were carried out according to the Ethics Committee, National Research Centre, Cairo, Egypt and followed the recommendations of the National Institutes of Health Guide for Care and Use of Laboratory Animals (Publication No. 85-23, revised 1985).

\section{Funding/Support}

Self-funding.

\section{References}

1. Ilaria L, Gennaro R, Francesco C, Giulia B, Luisa A, David $\mathrm{D}$, et al. Oxidative stress, aging, and diseases. Clin Interv Aging. 2018;13:757-72. doi: 10.2147/CIA.S158513

2. Vinod N. The aging brain: Recent research and concepts. Gerontol Geriatric Stud. 2017;1(3):GGS.000511. doi:10.31031/ggs.2017.01.000511.

3. Shwe T, Pratchayasakul W, Chattipakorn N, Chattipakorn SC. Role of D-galactose-induced brain aging and its potential used for therapeutic interventions. Exp Gerontol. 2018;101:13-36. doi:10.1016/j.exger.2017.10.029.

4. Ma Y, Ma B, Shang Y, Yin Q, Wang D, Xu S, et al. Flavonoidrich ethanol extract from the leaves of Diospyros kaki attenuates D-galactose-induced oxidative stress and neuroinflammation-mediated brain aging in mice. OxidMed Cell Longev. 2018;2018:1-12. doi:10.1155/2018/8938207.

5. Chen MH, Yang KM, Huang TC, Wu ML. Traditional small-size citrus from Taiwan: Essential oils, bioactive compounds and antioxidant capacity. Medicines. 2017;4:28. doi:10.3390/medicines4020028.

6. Wang Y, Zeng W, Xu P, Lan Y, Zhu R, Zhong K, et al. Chemical Composition and Antimicrobial Activity of the Essential Oil of Kumquat (Fortunella crassifolia Swingle) Peel. Int J Mol Sci. 2012;13(3):3382-93. doi:10.3390/ ijms13033382.

7. Lou SN, Ho CT. Phenolic compounds and biological activities of small-size citrus: Kumquat and calamondin. J Food Drug Anal. 2017;25(1):162-75. doi:10.1016/j. jfda.2016.10.024.

8. Allam MA, Khedr AA, El-Beltagy A. Kumquat as a potent natural material to improve lipid profile of hypercholesterolemic rats. Biolife. 2015;3(1):171-81.

9. Dosoky NS, Setzer WN. Biological Activities and Safety 
of Citrus spp. Essential Oils. Int J Mol Sci. 2018:19:1966. doi:10.3390/ijms19071966.

10. Nouri A, Shafaghatlonbar A. Chemical constituents and antioxidant activity of essential oil and organic extract from the peel and kernel parts of Citrus japonica Thunb. (kumquat) from Iran. Nat Prod Res. 2016;30(9):1093-7. do i:10.1080/14786419.2015.1101692.

11. Miranda RM, Dias DCFS, Picoli EAT, Silva PP, Nascimento WM. Physiological quality, anatomy and histochemistry during the development of carrot seeds (Daucus carota L.). Ciência e Agrotecnologia. 2017;41(2):169-80. doi:10.1590/1413-70542017412009216.

12. Aćimović M, Stanković J, Cvetković M, Ignjatov M, Nikolić L. Chemical characterization of essential oil from seeds of wild and cultivated carrots from Serbia. Botanica Serbica. 2016;40(1):55-60. doi:10.5281/zenodo.48861.

13. Singh K, Singh N, Chandy A, Manigauha A. In vivo antioxidant and hepatoprotective activity of methanolic extracts of Daucus carota seeds in experimental animals. Asian Pac J Trop Biomed. 2012;2(5):385-8. doi:10.1016/ s2221-1691(12)60061-6.

14. Shebaby WN, Daher CF, El-Sibai M, Bodman-Smith $\mathrm{K}$, Mansour A, Karam MC, et al. Antioxidant and hepatoprotective activities of the oil fractions from wild carrot (Daucus carota ssp. carota). Pharm Biol. 2015;53(9):1285-94. doi:10.3109/13880209.2014.976349.

15. Misiaka IJ, Lipoka J, Nowakowska EM, Wieczoreka PP, Mlynarz P, Kafarski P. Antifungal Activity of Carrot Seed Oil and Its Major Sesquiterpene Compounds. Zeitschrift für Naturforschung. 2004;59:791-6. doi:10.1515/znc-200411-1205.

16. Kumarasamy Y, Nahar L, Byres M, Delazar A, Sarker SD. The Assessment of Biological Activities Associated with the Major Constituents of the Methanol Extract of "Wild Carrot" (Daucus carota L.) Seeds. J Herb Pharmacother. 2005;5(1):61-72. doi:10.1300/j157v05n01_07.

17. Williams MA, Briggs GM. An evaluation of mineral mixtures commonly used in diets for experimental animals. Am J Clin Nutr. 1963;13(2):115-21. doi:10.1093/ ajcn/13.2.115.

18. Morcos SR. The effect of protein value of the diet on the neurological manifestations produced in rats by $\beta$-immodipropionitrile. Br J Nutr. 1967;21(2):269-74. doi:10.1079/bjn 19670029.

19. Singleton VL, Rossi JA. Colorimetry of total phenolics with phosphomolybdic- phosphotungstic acid reagents. Am J Enol Vitic. 1965;16:144-53.

20. Zhishen J, Mengcheng T, Jianming W. The determination of flavonoid contents of mulberry and their scavenging effects on superoxide radicals. Food Chem. 1999;64(4):555-9. doi:10.1016/s0308-8146(98)00102-2.

21. Association of Official Analytical Chemists (AOAC). Official Methods of Analysis. 17th ed. Washington DC, USA: AOAC; 2000.

22. Satoh K. Serum lipid peroxide in cerebrovascular disorders determined by a new colorimetric method. Clin Chim Acta. 1978;90(1):37-43.doi:10.1016/0009-8981(78)90081-5.

23. Aebi H. Catalase in vitro. Methods Enzymol. 1984;105:1216.doi:10.1016/s0076-6879(84)05016-3.

24. Vaisi-Raygani A, Rahimi Z, Kharazi H, Tavilani H, Aminiani
M, Kiani A, et al. Determination of butyrylcholinesterase (BChE) phenotypes to predict the risk of prolonged apnea in persons receiving succinylcholine in the healthy population of western Iran. Clin Biochem. 2007;40:629-33. doi:10.1016/j.clinbiochem.2007.01.018.

25. Reitman S, Frankel S. A Colorimetric method for the determination of serum glutamic oxalacetic and glutamic pyruvic transaminases. Am J Clin Path. 1957;28(1):56-63. doi:10.1093/ajcp/28.1.56.

26. Houot O. Kinetic determination of creatinine. In: Henny J, Siest G, Schiele F, Young DS, ed. Interpretation of Clinical Laboratory Tests. USA, California: Biomedical Publications; 1985. p. 220-34.

27. Fawcett JK, Scott JE. A rapid and precise method for the determination of urea. J Clin Pathol. 1960;13(2):156-9. doi:10.1136/jcp.13.2.156.

28. Sgarbieri VC, Pacheco MTB. Healthy human aging: intrinsic and environmental factors. Braz J Food Technol. 2017;20:e2017007. doi:10.1590/1981-6723.00717.

29. Lim SY, Kim EJ, Kim A, Lee HJ, Choi HJ, Yang SJ. Nutritional factors affecting mental health. Clin Nutr Res. 2016;5(3):143-52. doi:10.7762/cnr.2016.5.3.143.

30. Soutif-Veillon A, Ferland G, Rolland Y, Presse N, Boucher $\mathrm{K}$, Féart $\mathrm{C}$, et al. Increased dietary vitamin $\mathrm{K}$ intake is associated with less severe subjective memory complaint among older adults. Maturitas. 2016;93:131-6. doi:10.1016/j. maturitas.2016.02.004.

31. Luceri C, Bigagli E, Pitozzi V, Giovannelli L. A nutrigenomics approach for the study of anti-aging interventions: olive oil phenols and the modulation of gene and microRNA expression profiles in mouse brain. Eur J Nut. 2017;56(2):865-77. doi:10.1007/s00394-015-1134-4.

32. Fatemi I, Khaluoi A, Kaeidi A, Shamsizadeh A, Heydari S, Allahtavakoli M. Protective effect of metformin on D-galactose-induced aging model in mice. Iran J Basic Med Sci. 2018;21:19-25. doi:10.22038/IJBMS.2017.24331.6071.

33. Qing W, Li F, Wang X, Quan C, Ouyang W, Liao Q. Inhibiting RIP1 improves chronic stress-induced cognitive impairments in D-galactose-induced aging mice. Front Behav Neurosci. 2018;12:234. doi:10.3389/ fnbeh.2018.00234.

34. Wu H, Chen M, Yan P, Yao Q, Fan J, Gao Z, et al. Erythropoietin suppresses D-galactose-induced aging of rats via the PI3K/Akt/Nrf2-ARE pathway. Int J Clin Exp Pathol. 2018;11(4):2227-40.

35. Lou SN, Lai YC, Hsu YS, Ho CT. Phenolic content, antioxidant activity and effective compounds of kumquat extracted by different solvents. Food Chem. 2016;197:1-6. doi:10.1016/j.foodchem.2015.10.096.

36. Yu L, Yan J, Sun Z. D-limonene exhibits anti-inflammatory and antioxidant properties in an ulcerative colitis rat model via regulation of iNOS, COX-2, PGE2 and ERK signaling pathways. Mol Med Rep. 2017;15(4):2339-46. doi:10.3892/ mmr.2017.6241.

37. Sarubbo F, Moranta D, Miralles A, Esteban S. Polyphenols What's Behind their Antiaging Brain Reputation? Ann Nutr Food Sci. 2018;1(2):1009.

38. Hosseini SF, Amraie M, Salehi M, Mohseni M, Aloui H. Effect of chitosan-based coatings enriched with savory and/ or tarragon essential oils on postharvest maintenance of 
kumquat (Fortunella sp.) fruit. Food Sci Nutr. 2019;7(1):15562. doi:10.1002/fsn3.835.

39. Monacelli F, Acquarone E, Giannotti C, Borghi R, Nencioni A. Vitamin C, Aging and Alzheimer's disease. Nutrients. 2017;9(7):670. doi:10.3390/nu9070670.

40. Mani V, Parle M. Pharmalogical evidence for potential of Daucus carota in the management of cognitive dysfunctions. Biol Pharm Bull. 2006;29(6):1154-61. doi:10.1248/ bpb.29.1154.

41. Mani V, Parle M, Ramasamy K, Majeed ABA. Antidementia potential of Daucus carota seed extracts in rats. Pharmacologyonline. 2010;1:552-65.

42. Ksouri A, Dob T, Belkebir A, Krimat S, Chelghoum C. Chemical composition and antioxidant activity of the essential oil and the methanol extract of Algerian wild carrot Daucus carota L. ssp. carota. (L.) Thell. J Mater Environ Sci. 2015;6(3):784-91.

43. Rezaei-Maghadam A, Mohajeri D, Rafiei B, Dizaji R, Azhdari A, Yegomehzad M, et al. Effect of tumeric and carrot seed extracts on serum liver biomakers and hepatic lipid peroxidation, antioxidant enzymes and total antioxidant status in rats. Bioimpacts. 2012;2:151-7. doi:10.5681/bi.2012.020.

44. Manzari-Tavakoli A, Pouraboli I, Yaghoobi MM, Mehrabani M, Mirtadzadini SM. Antihyperglycemic, antilipid peroxidation and insulin secretory activities of
Otostegia persica shoot extract in streptozotocin-induced diabetic rats and in vitro $\mathrm{C} 187$ pancreatic $\beta$-cells. Pharm Biol. 2013;51(2):253-9. doi:10.3109/13880209.2012.718351.

45. Higdon JV, Frei B. Tea catechins and polyphenols: health effects, metabolism, and antioxidant functions. Crit Rev Food Sci Nutr. 2003;43(1):89-143. doi:10.1080/10408690390826464.

46. Hussain G, Schmitt F, Loeffler JP, Gonzalez de Aguilar JL. Fatting the brain: a brief of recent research. Front Cell Neurosci. 2013;7:144. doi:10.3389/fncel.2013.00144.

47. Ochoa JJ, Pamplona R, Ramirez-Tortosa MC, GranadosPrincipal S, Perez-Lopez P, Naudí A, et al. Age-related changes in brain mitochondrial DNA deletion and oxidative stress are differentially modulated by dietary fat type and coenzyme Q1. Free Radic Biol Med. 2011;50(9):1053-64. doi:10.1016/j.freeradbiomed.2011.02.004.

48. Amtul Z, Uhrig M, Rozmahel RF, Beyreuther K. Structural insight into the differential effects of omega-3 and omega- 6 fatty acids on the production of A-beta peptides and amyloid plaques. J Biol Chem. 2011;286(8):6100-7. doi:10.1074/jbc. m110.183608.

49. Amtul Z, Westaway D, Cechetto DF, Rozmahel RF. Oleic acid ameliorates amyloidosis in cellular and mouse models of Alzheimer's disease. Brain Pathol. 2011;21(3):321-9. doi:10.1111/j.1750-3639.2010.00449.x. 